\title{
Prosthetic Rehabilitation of Acquired Maxillary Defects Secondary to Mucormycosis: Clinical Cases
}

\author{
${ }^{1}$ Rupal J Shah, ${ }^{2}$ Manish Khan Katyayan, ${ }^{3}$ Preeti Agarwal Katyayan, ${ }^{4}$ Vishal Chauhan
}

\begin{abstract}
Maxillary necrosis can occur due to bacterial infections such as osteomyelitis, viral infections, such as herpes zoster or fungal infections, such as mucormycosis, aspergillosis etc. Mucormycosis is an opportunistic fungal infection, which mainly infects immunocompromised patients. Once the maxilla is involved, surgical resection and debridement of the necrosed areas can result in extensive maxillary defects. The clinician is to face many a challenge in order to replace not only the missing teeth, but also the lost soft tissues and bone, including hard palate and alveolar ridges. The prosthesis (Obturator) lacks a bony base and the lost structures of the posterior palatal seal area compromise retention of the prosthesis. Furthermore, the post surgical soft tissues are scarred and tense, which exert strong dislodging forces. The present article describes the prosthetic rehabilitation of maxillary necrosis secondary to mucormycosis in two cases, one completely edentulous and the other partially edentulous.
\end{abstract}

Keywords: Mucormycosis, Obturator, Removable appliances.

How to cite this article: Shah RJ, Katyayan MK, Katyayan PA, Chauhan V. Prosthetic Rehabilitation of Acquired Maxillary Defects Secondary to Mucormycosis: Clinical Cases. J Contemp Dent Pract 2014;15(2):242-249.

Source of support: Nil

Conflict of interest: None declared

\section{INTRODUCTION}

The maxilla rarely undergoes necrosis due to its rich vascularity. Maxillary necrosis can occur due to bacterial infections, such as osteomyelitis, viral infections, such as herpes zoster or fungal infections, such as mucormycosis, aspergillosis, etc. Mucormycosis is an opportunistic fungal infection, which mainly infects immunocompromised patients. The infection begins in the nose and paranasal sinuses due to inhalation of fungal spores. ${ }^{1}$ The infection

\footnotetext{
${ }^{1}$ Professor and Head, ${ }^{2-4}$ Assistant Professor

1,3,4 Department of Prosthodontics, Government Dental College and Hospital, Ahmedabad, Gujarat, India

${ }^{2}$ Department of Dentistry, GMERS Medical College Gandhinagar, Gujarat, India

Corresponding Author: Manish Khan Katyayan, Assistant Professor, Department of Dentistry, GMERS Medical College Gandhinagar, Gujarat, India, Phone: 091-7600807617, e-mail: drkatyayan@ymail.com
}

can spread to orbital and intracranial structures either by direct invasion or through the blood vessels. The fungus invades arteries leading to thrombosis that subsequently causes necrosis of hard and soft tissue. ${ }^{1,2}$ Once entered into the arteries, the fungus can spread to orbital and intracranial structures. ${ }^{3,4}$ Maxillary osteomyelitis due to mucormycosis though rare, can develop with number of predisposing conditions, such as diabetes mellitus, renal failure, malignancies, IV drug abusers, malnutritional states, as well as immunosuppression and steroid therapy., ${ }^{4,5}$

Once the maxilla is involved, surgical resection and debridement of the necrosed areas can result in extensive maxillary defects. The defect may be in the form of a small opening resulting in communication from the oral cavity into the maxillary sinus, or it may include portion of the hard and soft palate, alveolar ridge and the floor of the nasal cavity. ${ }^{6}$ In most of the patients treated, varying amounts of palatal and alveolar tissues remain on the non-defect side, making prosthodontic rehabilitation relatively simple and predictable. ${ }^{7}$ However, in patients with extensive removal of the maxilla, there are not only challenges to be faced by the patient, but treatment requires a different approach with extensive surgical and prosthodontic rehabilitation.

Complete removal of the hard palate may result in hypernasal/unintelligible speech in addition to masticatory difficulties, as the tongue is unable to make contact with a solid surface during these functions. In case of oronasal/ oroantral communications, there may be fluid leakage through the nose, and maybe associated with acute and chronic episodes of sinusitis. ${ }^{7-11}$ There may be cosmetic deformities, such as collapse of the middle third of face, ${ }^{12}$ and this may be accompanied by dental and temporomandibular joint problems. ${ }^{13}$

The clinician is to face many a challenge in order to replace not only the missing teeth, but also the lost soft tissues and bone, including hard palate and alveolar ridges. The prosthesis (obturator) lacks a bony base and the lost structures of the posterior palatal seal area compromise retention of the prosthesis. Furthermore, the post surgical soft tissues are scarred and tense, which exert strong dislodging forces. The prosthesis that replaces all of the missing structures will invariably be bulky, and the added weight and volume further complicates retention of the prosthesis. ${ }^{6,7,10,11,14}$ In addition, excess resorption of the 
residual edentulous ridges may be encountered, demands equalization of stress distribution to available portions of the palate. In such conditions retention stability and support can be enhanced by maximum preservation of hard palate, skin grafting the cheek and maxillary sinus wall for better support and removal of inferior turbinates to provide a larger surface area for stress distribution. ${ }^{15}$

The present article describes the prosthetic rehabilitation of maxillary necrosis secondary to mucormycosis in two cases, one completely edentulous and the other partially edentulous.

\section{CASE REPORTS}

\section{Case 1}

A 48-year-old woman reported to the Department of Prosthetic Dentistry, Government Dental College and Hospital, Ahmedabad for prosthetic rehabilitation of an acquired maxillary defect secondary to mucormycotic necrosis. Patient gave a history of a series of surgical procedures that were carried out in order to remove the necrotized and denuded hard and soft tissues of the maxilla. The patient's medical history revealed no major systemic illness. Patient's Orthopantomogram (OPG) and CT scan showed bone defect in the floor of both maxillary sinuses and hard palate, along with removal of the entire maxillary alveolus (Figs 1A to F) A surgical history revealed that after the inferior-lateral maxillectomy, buccal mucoperiosteal flaps were used for closure of oroantral communications resulting from removal of necrosed bone in hard palate. Two lateral openings in the remnants of the maxillary sinuses were created on either side, because the surgeon believed these could be used to help retain a future prosthesis.

On intraoral examination, it was found that all the maxillary teeth and residual alveolar ridge were absent. Majority of the hard palate bone was missing on palpation and its soft tissue surface was mobile. The roof of the patient's mouth was lined palatal mucoperiosteum and had openings into the maxillary sinus (approximately $0.5 \times 2.0 \mathrm{~cm}$ ) on either side (Fig. 2). The buccal and labial vestibules were obliterated. The mandibular arch was completely dentulous and unaffected by the condition of the maxilla. Mandibular movements were within the normal range, there was no supraeruption of mandibular teeth and tongue function was normal.

The patient presented with obvious difficulty in mastication, deglutition and speech. There was also an esthetic setback as the middle third of the face appeared collapsed. The prosthetic difficulties one could foresee were the lack of a firm, immobile bony basal seat for denture support; absence of ridges or remaining teeth to help retain a prosthesis; the absence of residual alveolar ridges to indicate the lateral tooth position during teeth arrangement, and obliteration of the labial and buccal vestibules - a condition which tends to dislodge a prosthesis.

In order to make the preliminary impression of the patient's maxillary arch, the two lateral oronasal openings were first packed with gauze that was tied for retrieval after impression making, and then impression compound (Y-Dents, Delhi, India) was used to record the impression in a selected stock metal tray. The preliminary impression of mandibular arch was made with irreversible hydrocolloid.

The impressions were then poured in type II gypsum product (Dental plaster; Kalabhai Karson, Mumbai, India) and preliminary casts were obtained. Over the maxillary cast, a custom tray was fabricated with auto-polymerizing resin material. (DPI RR Cold Cure; Dental Products of India, Mumbai, India) the custom tray was made to extend into the two oronasal openings on either side, such that it could carry the impression material up to $5 \mathrm{~mm}$ into the defect area. Peripheral molding was done with green stick compound (DPI Pinnacle, Tracing Sticks Dental Products of India, Ltd) and a final or wash impression was made with light body polyvinyl siloxane elastomer (3M ESPE Express Std., Germany).

A master cast was poured into this impression with type III gypsum product (Kalstone; Kalabhai Karson, Mumbai, India) and an auto-polymerizing resin record base (DPI RR Cold Cure; Dental Products of India, Mumbai, India) and record rim from modeling wax (Modeling wax; Deepti Dental Products, Ratnagiri, India) was fabricated. Maxillomandibular relations were recorded. The final arch form and tooth position of maxillary anterior teeth was determined by phonetics and esthetics. Longer maxillary anterior teeth were selected for adequate lip support and visibility. The arrangement of the six anterior teeth was first guided by lip position, nasolabial angle, and tooth-to-lip relations. Their position was verified with phonetic tests that required the patient to pronounce $/ \mathrm{s} /, / \mathrm{f} /, / \mathrm{v} /$, and $/ \mathrm{th} /$ sounds. ${ }^{16-18}$ The position of maxillary posterior teeth was guided by the position of mandibular posterior teeth. The prosthesis was tried in and was then processed in thermoplastic resin (Valplast) in order to reduce the weight of the final prosthesis (Fig. 3).

On delivery of the finished prosthesis or obturator, careful occlusal adjustments were performed to ensure that dislodging interferences were minimized wherever possible. The extensions of the prosthesis into the oronasal communications were checked for slightly adjusted to eliminate any soft tissue irritation in the area. The patient was trained regarding the removal and insertion of prosthesis and post insertion instructions were given. The patient was recalled after 24 hours for a follow-up. Recall visits were scheduled after 1 week, 1,3 , and 6 months, and 1 year with satisfactory 

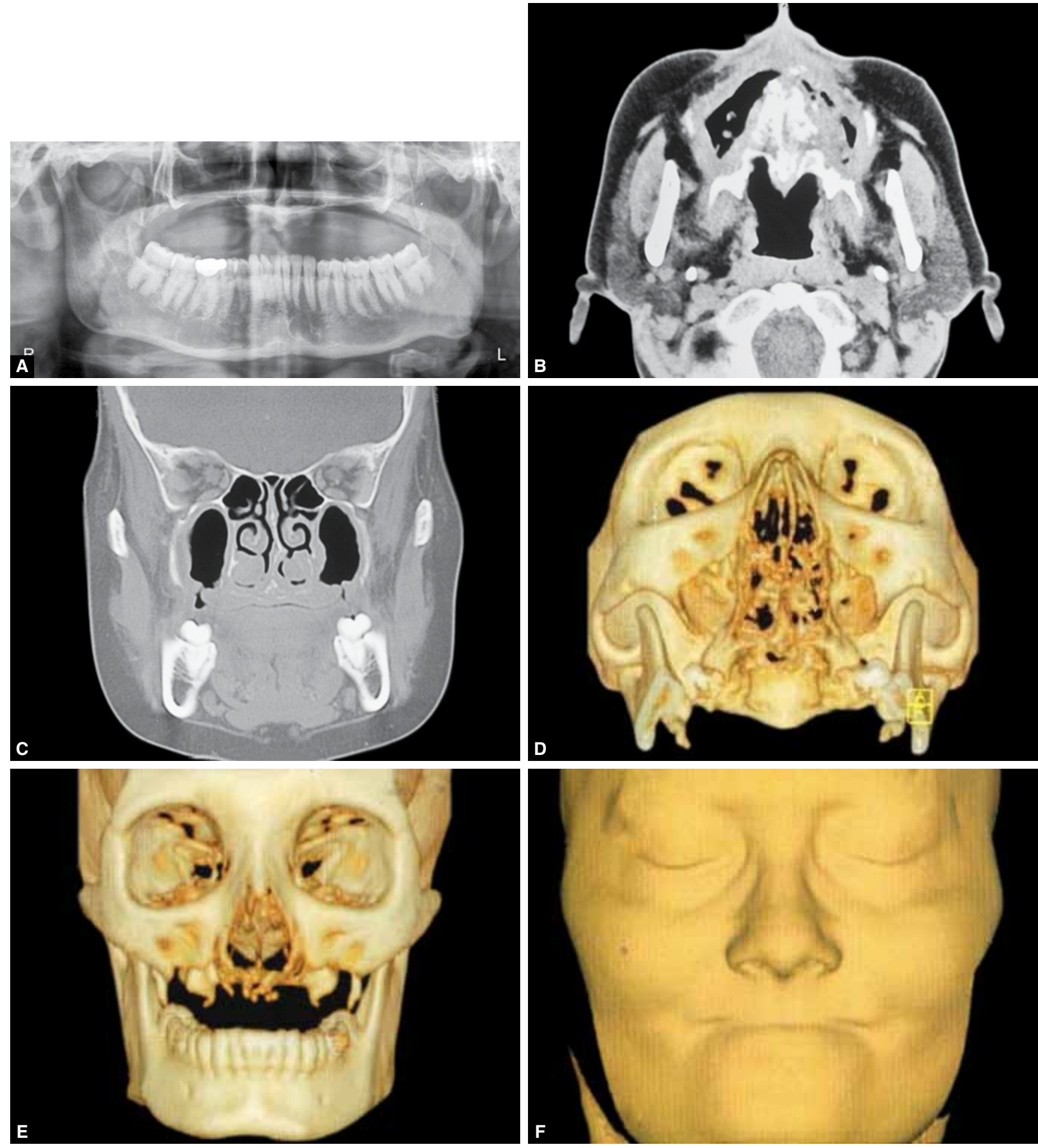

Figs 1A to F: (A) Orthopantogram showing completely edentulous maxilla with palatal defect, (B) Post- contrast axial CT scan of cranium showing maxillary defect, (C) Coronal CT scan slice suggesting loss of maxillary alveolus and dentition, (D) Three dimensional reconstruction of axial CT scan of skull showing maxillary defect (E) Three dimensional reconstruction of coronal CT scan of skull showing loss of maxillary alveolus and dentition, (F) Three dimensional face reconstruction

results. The patient adapted well to her prosthesis and not only perceived that her speech had returned to near normal, but she reported good masticatory ability and was satisfied with the cosmetic outcome (Figs 4A to D).

After a period of 5 years, a follow-up was done and the prosthesis was evaluated. The prosthesis showed satisfactory retention and esthetics, was well maintained, except for discoloration of the valplast resin and a few stains on the polished surface, and the patient was still able to perform masticatory functions well with the prosthesis (Figs $5 \mathrm{~A}$ to D).

\section{Case 2}

Another female patient, 42 years of age, presented a similar history of an acquired maxillary defect as a result of surgical treatment for mucormycotic osteomyelitis. On examination, the maxilla showed two oronasal openings, one in the 


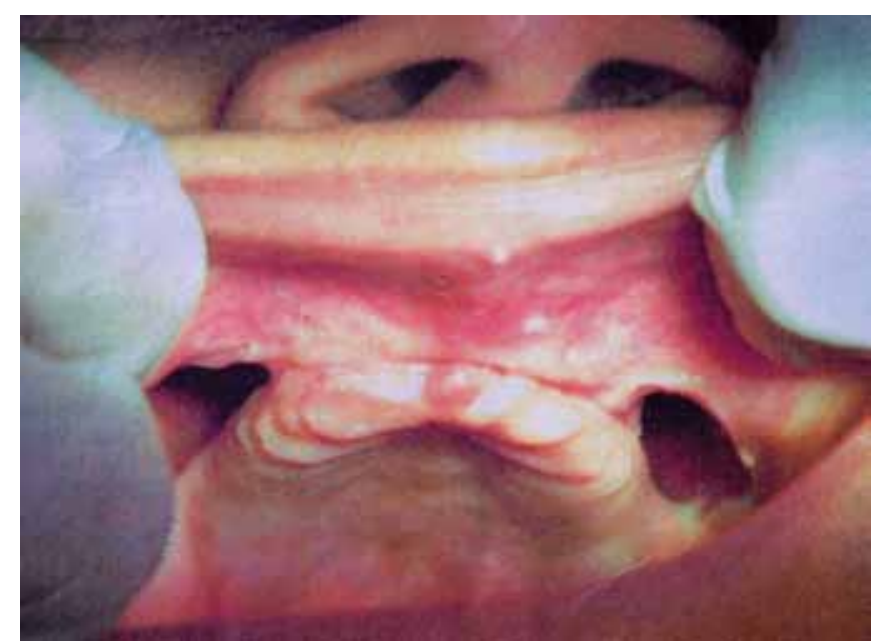

Fig. 2: Intraoral view of the defect
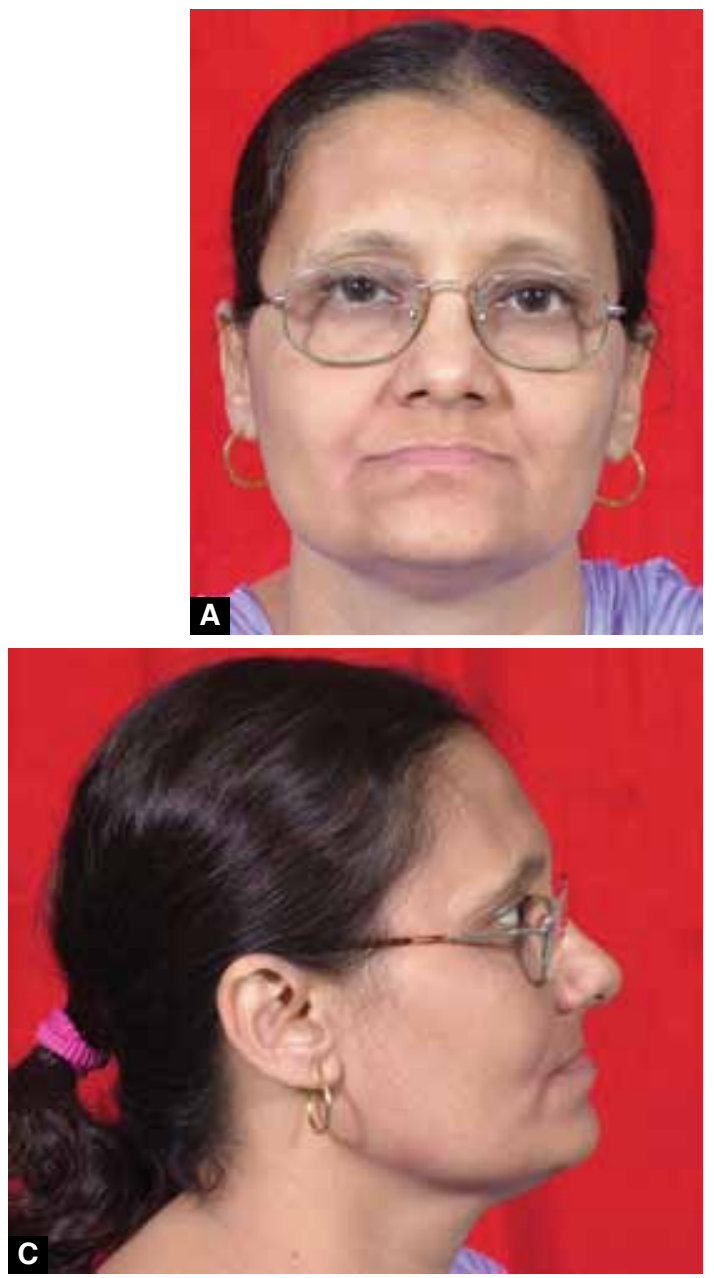

Figs 4A to D: (A) Facial esthetics before prosthesis (Frontal), (B): Facial esthetics after prosthesis (Frontal)

(C) Facial esthetics before prosthesis (Profile), (D): Facial esthetics after prosthesis (Profile)

center of the palate $(0.5 \times 0.5 \mathrm{~cm}$ in size $)$ and another unilaterally in the region of left alveolar ridge posterior to the first maxillary premolar. On palpation, large sections of the hard palate adjacent to the defect areas were missing. The left maxillary second premolar and molars, along with their alveolus, were missing (Fig. 6). The remaining natural teeth in the maxillary arch, and the alveolus associated with

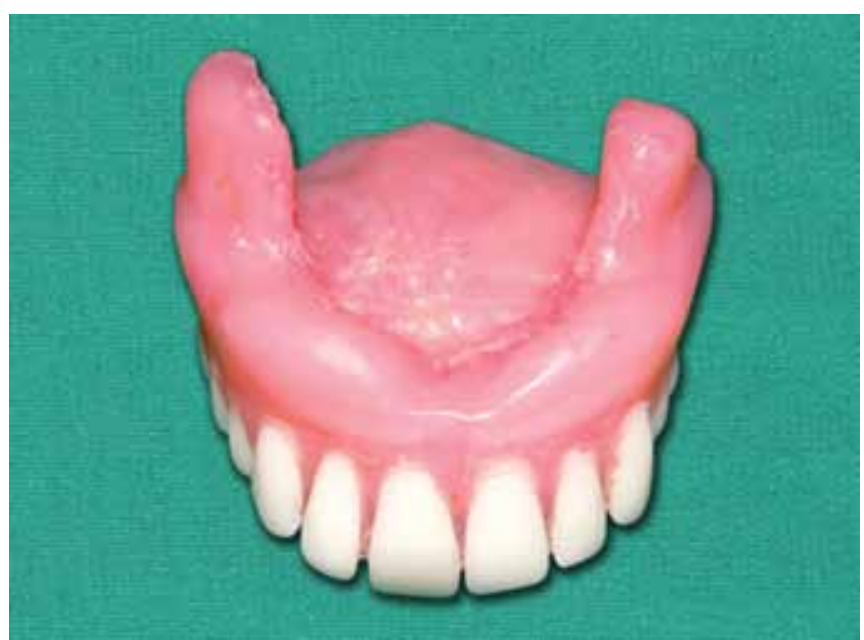

Fig. 3: Final prosthesis
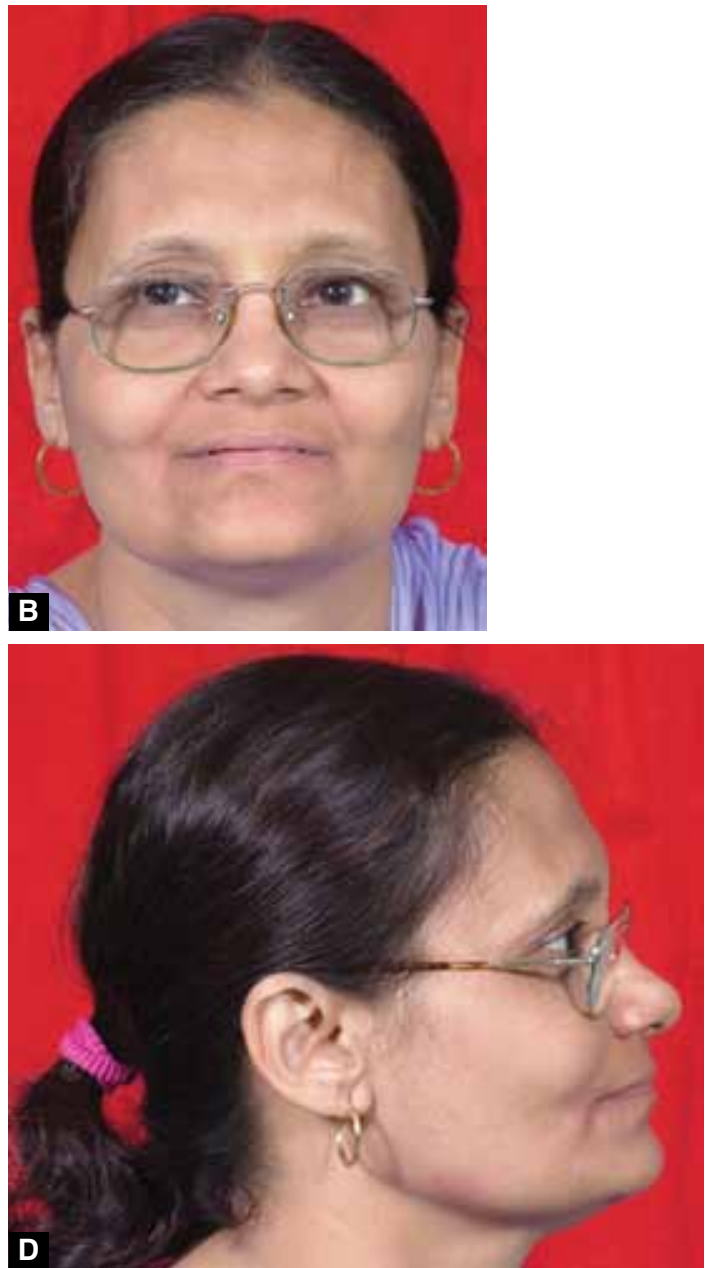

them, were healthy. The mandibular arch was intact and normal mandibular function was observed.

The maxillary oronasal areas were packed with gauze tied to floss and preliminary impressions of both the arches were made with irreversible hydrocolloid (Zelgan 2002, Dentsply, India), (Fig. 7), and poured in type II gypsum material (Dental plaster; Kalabhai Karson, Mumbai, India). 

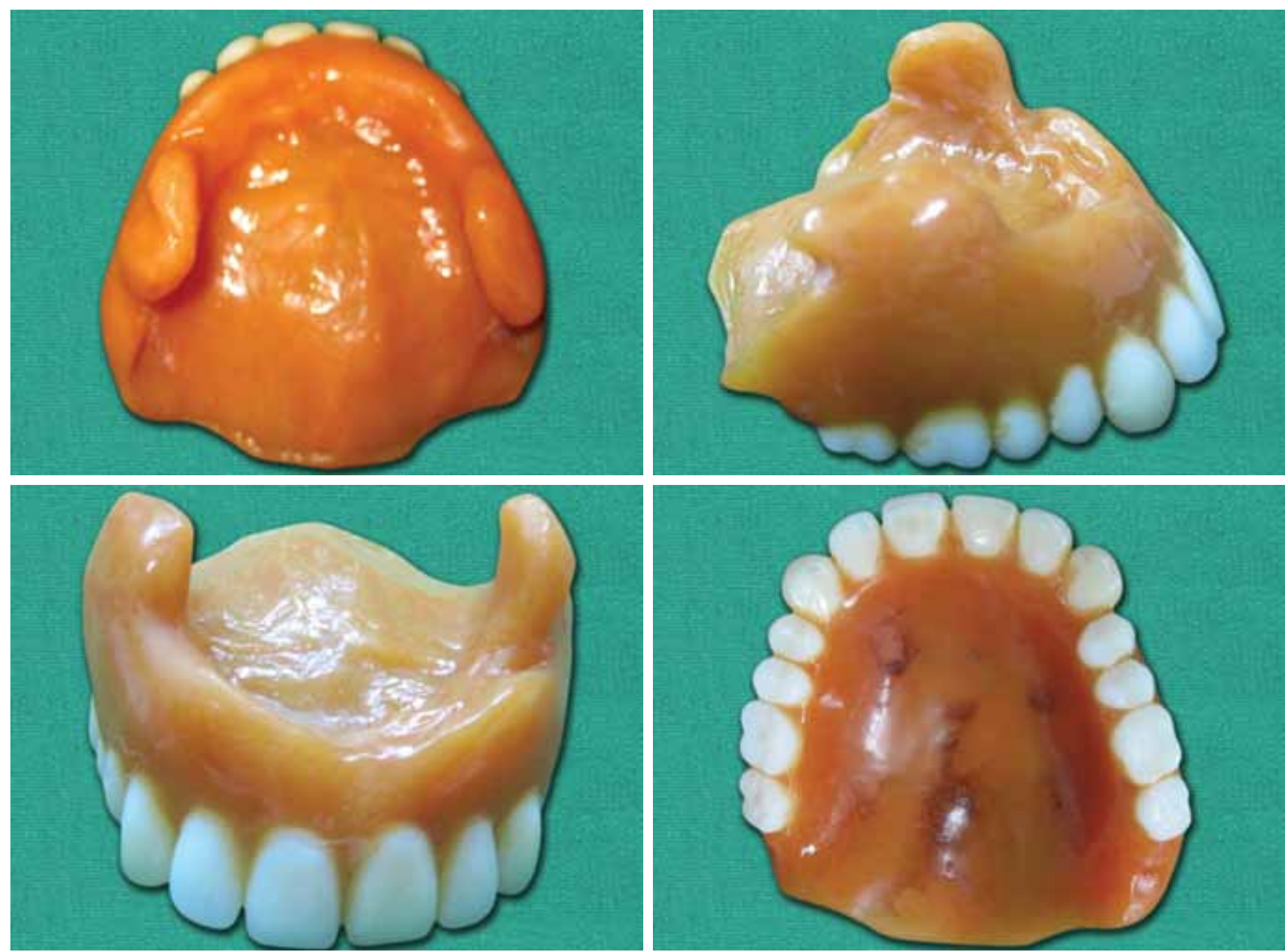

Fig. 5: Prosthesis after 5 years follow-up

Over the maxillary cast, a custom tray was fabricated with auto-polymerizing resin (DPI RR Cold Cure; Dental Products of India, Mumbai, India). Border molding was carried out with green stick compound (DPI Pinnacle, Tracing Sticks Dental Products of India Ltd) and a secondary impression was made with medium body polyvinyl siloxane elastomer (Examix NDS, GC America Inc., Alsip, Illinois) (Fig. 8). It was poured in type III gypsum material (Kalstone; Kalabhai Karson, Mumbai, India) to obtain a final cast (Fig. 9). A record base was fabricated with an Adam's clasp on the right maxillary first molar and C-clasps on right maxillary first premolar and left maxillary canine. Record rims were made and jaw relations were recorded. In the edentulous space, two maxillary molar teeth were arranged instead of the missing three teeth, as extending the occlusal table further posteriorly over a non-bony support area would cause unwanted leverage over the prosthesis during masticatory function (Fig. 10). The prosthesis was tried in, and then processed in conventional heat cure acrylic resin (Lucitone 199, Dentsply, York PA, USA), (Fig. 11). The clasps were retained in the final prosthesis, whose denture base extended well into the oronasal openings and acted as retentive aids in addition to the retentive clasps.
Necessary adjustments were made to fit the prosthesis intraorally (Fig. 12). The prosthesis was delivered to the patient with reinforcement of post-insertion care and recalled at the interval of 3 months for initial 1 year followed by every 6 months. The patient was satisfied with the functional outcome of the prosthesis.

\section{DISCUSSION}

Oroantral communications can be a source of discomfort because of food and fluids entering the sinus cavities, thereby predisposing patients to sinusitis and middle ear infections. Whenever possible, oronasal communications should be considered for surgical closure. Because they provided the only means of retention for the prosthesis described in the case of the edentulous patient, and additional means of retention in the dentulous patient (due to the probability of involvement and extraction of remaining teeth in the future), the oronasal communications were purposely kept patent by the acrylic resin extensions of the denture. This form of retention, though unconventional, can be effective and should be considered for similarly impaired patients when conventional forms of retention, including osseointegrated implants, are not a treatment option. 


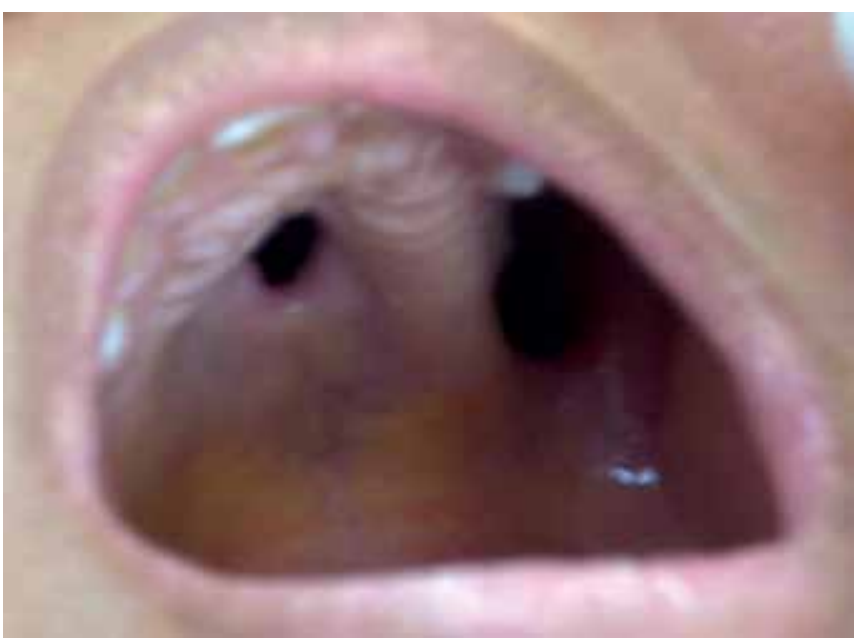

Fig. 6: Intraoral defect

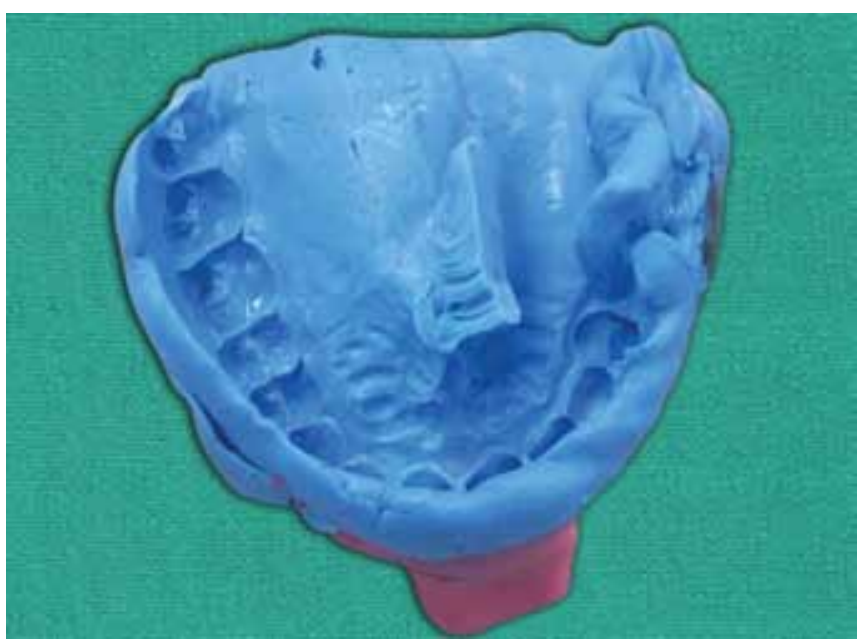

Fig. 8: Secondary impression

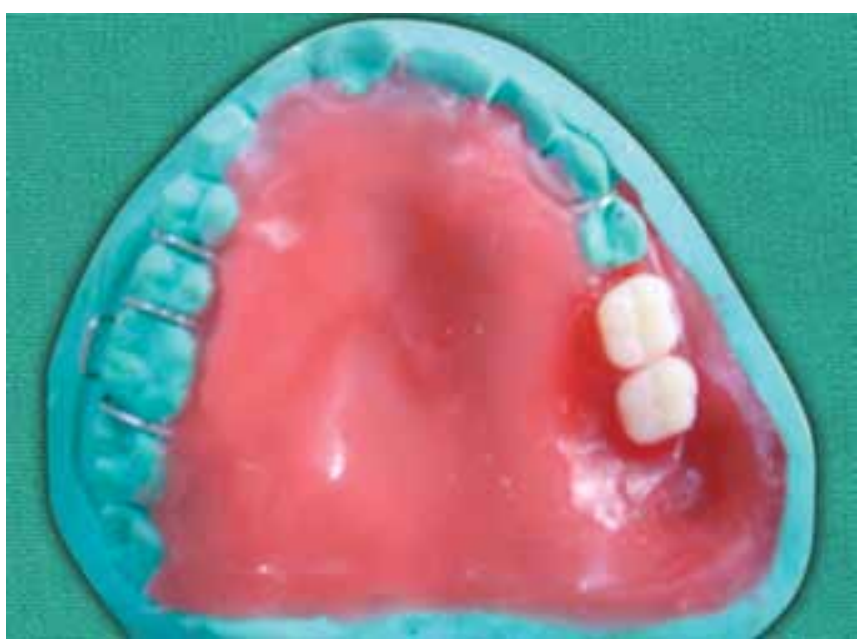

Fig. 10: Final wax-up

Maxillofacial rehabilitation is a multidisciplinary task. Communication with the surgeon as far as extent of disease, precise surgical technique, anticipated postoperative defects and healing time could help to plan the treatment. It is well established, among those involved in maxillofacial rehabilitation, that the fewer the teeth remaining in the arch, the more complicated is the closure of the maxillary

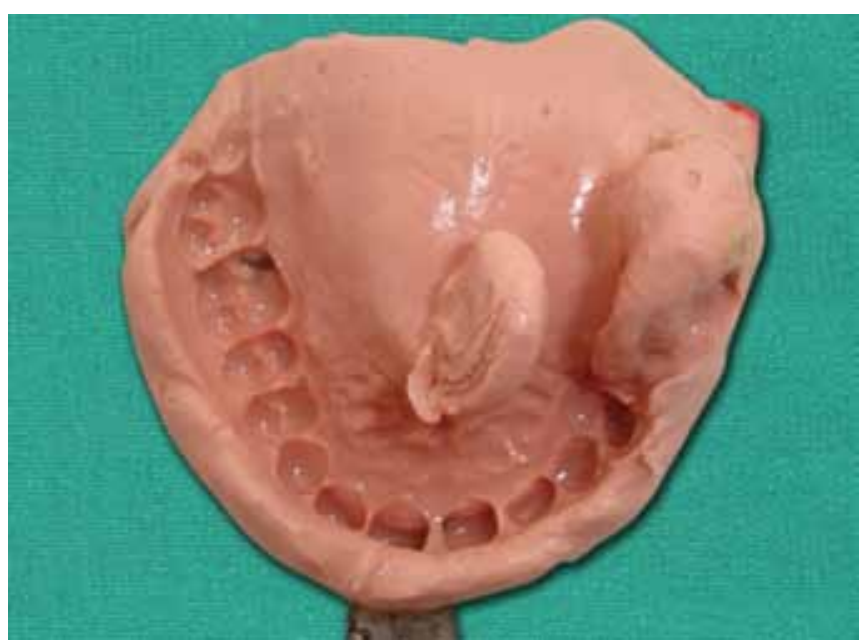

Fig. 7: Preliminary impression

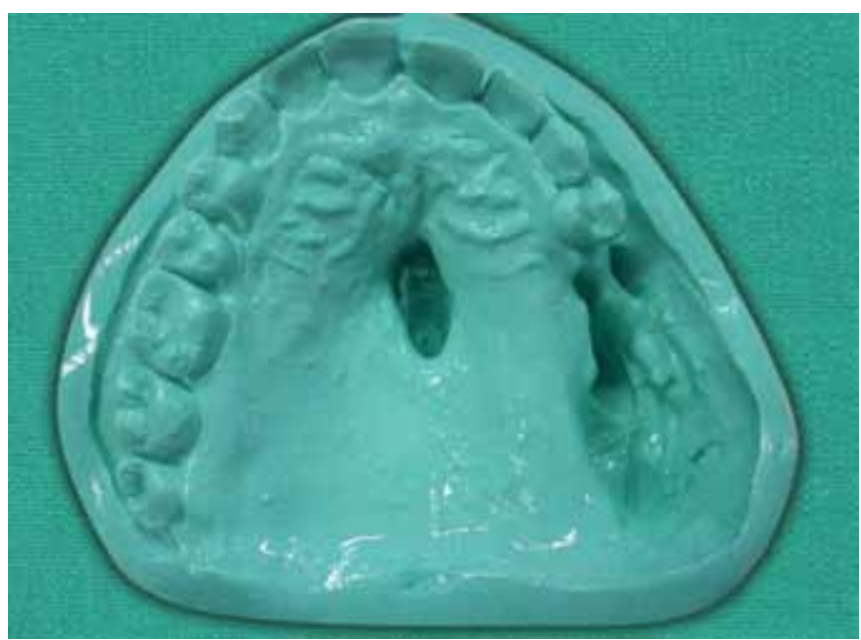

Fig. 9: Final cast

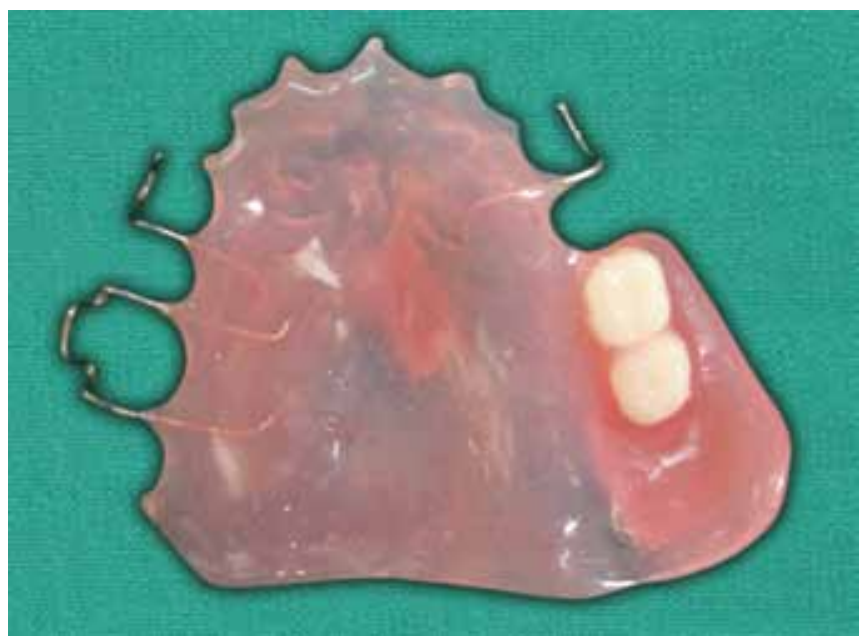

Fig. 11: Prosthesis

defects by means of flaps. In particular, the separation between the oral and nasal cavity with a muscular diaphragm which does not rest on hard tissue leads to a mobile support, for which it is impossible to carry out adequate impressions. Moreover, the support thus provided to the prosthesis gives way during mastication loads. Recommendations can be made for the preservation of tissues or to improve the 


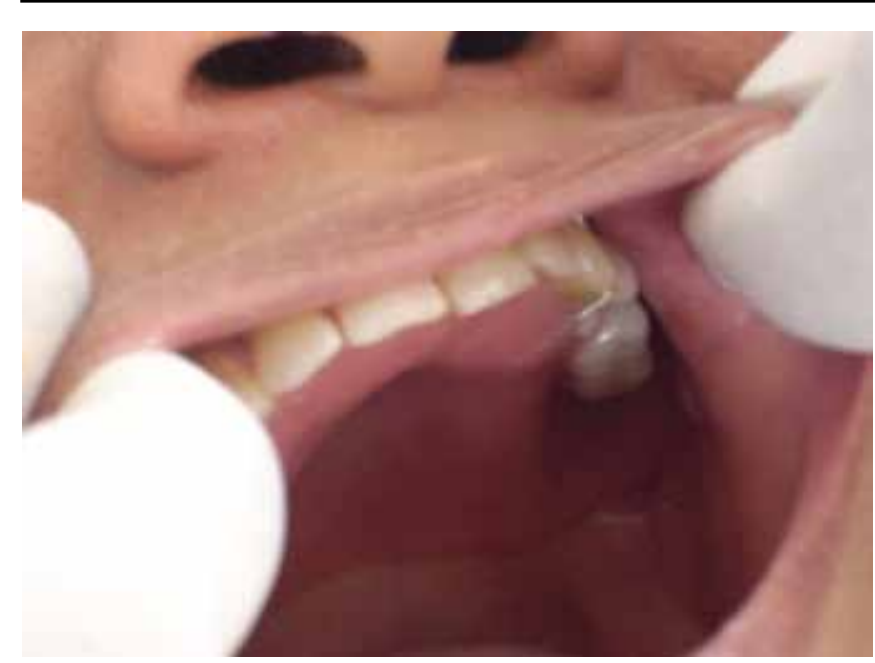

Fig. 12: Intraoral view

existing anatomical structures to improve the retention, stability and support for the prosthesis. ${ }^{19}$

Coordination with speech pathologist to gain knowledge about mechanics and physiology of speech can help to design the prosthesis, which can fulfill the requirements of resonance, phonation and articulation. ${ }^{6}$

In the above presented cases, our aim was to eliminate the communication of the oral and nasal cavity by way of an obturator prosthesis, providing adequate functions of chewing, swallowing, and speech, as well as acceptable esthetic appearance.

There are various factors associated with satisfactory phonetics in maxillary complete denture wearers, and these are critical in patients who are looking forward to be able to make intelligible speech with the help of such a prosthesis. These factors include the labial or palatal placement of the anterior teeth; the coverage of the hard palate; correct vertical dimension of occlusion; artificial teeth which may disturb the air flow, causing misarticulation, and the concavity of the palatal vaults of maxillary complete dentures. ${ }^{20}$ In the construction of a removable denture, the design of the alveolar area is crucial because, during speech, the tongue comes into contact with sections of teeth, alveolar ridge and hard palate. ${ }^{2}$ A rule to create an acceptable maxillary complete denture from the phonetic perspective is to set up the incisors 8 to $10 \mathrm{~mm}$ labial to the incisal papilla, as suggested by many Authors. ${ }^{22,23}$ The other two major determinants of anterior tooth position being esthetics and occlusion, the final placement of anterior teeth should integrate these too, for the prosthesis to have a successful functional and esthetic outcome. In the edentulous patient, in order to correct the esthetic problem of the collapsed upper lip due to subtotal maxillectomy, longer anterior teeth were selected with a slightly pronounced proclination, and the set up was tried in for satisfactory phonetics and esthetics. The palatal contour of the prosthesis was also waxed to achieve good phonetics.

The success of a total or subtotal bilateral obturator depends on the volume of the defect and on the remaining soft and hard palate, essential for retention, stabilization and support to the prosthesis. The weight of the obturator can act as a dislocating force; hence the prosthesis should be as light as possible. ${ }^{10}$ Valplast was used to process the obturator in the completely edentulous patient, as it offered several advantages. According to the properties of the valplast that has been claimed by previous researches, ${ }^{24-28}$ it is expected that the material would be of great help in improving the retention of the obturators by its resiliency and its elastic memory that can catch the undercut inside the surgical cavity without causing tissue injury to the sensitive tissue at this area. Meanwhile it would also seal the surgical cavity preventing any seepage and in the same time improve speech ability. It would also improve patient satisfaction because it is light in weight. Good biocompatibility is achieved because the material is free of monomer and metal, these being the principle causes of allergic reactions in conventional denture materials. $^{29-34}$

The two oronasal openings, though critical for retention, were sensitive to irritation and the defect area/areas always need to be relieved of pressure under the prosthesis. Thus, careful adjustments had to be made in the corresponding extensions of the prosthesis. Although we have advanced materials to cope with the critical areas, there are some limitations in their use. Permanent soft liners can be used to reduce the pressure on the defect areas, as they provide the cushioning effect between the defect margins and the prosthesis. ${ }^{35,36}$ Also, they provide flexibility to the obturator, which allows its relatively simple placement in retentive undercut regions. But, as soft liners need repetitive replacement, it is better to avoid using them for fabricating a definite maxillofacial prosthesis, thus limiting their use only till the recently created defects. ${ }^{37}$ In addition, one study showed that soft liners in contact with nasal mucosa are more prone to fungal contamination than acrylic resin; ${ }^{38}$ it therefore is recommended that the use of soft liners be avoided in prostheses that contact nasal mucosa whenever possible.

Long-term follow-up and evaluation with an eye to the possibility of lesion recurrence is a part of the crucial contribution by the prosthodontist. ${ }^{39}$

\section{CONCLUSION}

Definitive prosthodontic treatment is one of the final therapies which are instituted and it attempts to alleviate any anatomical and functional deficiencies. This clinical report describes the prosthetic rehabilitation of two patients with subtotal maxillectomy due to mucormycotic osteonecrosis. 
Both the patients adapted well to their prosthesis. The benefits of these prostheses was that the technique followed were noninvasive, economical, tissue tolerant, esthetic to the patient, comfortable to use, easy to fabricate and clean, and with reported improvements in both speech and mastication with its use.

\section{REFERENCES}

1. Leitner C, Hoffmann J, Zerfowski M, Reinert S. Mucormycosis: necrotizing soft tissue lesion of the face. J Oral Maxillofac Surg 2003;61(11):1354-1358.

2. Pogrel MA, Miller CE. A case of maxillary necrosis. J Oral Maxillofac Surg 2003;61(4):489-493.

3. Zapico ADV, Suarez AR, Encinas PM, Angulo CM, Pozuelo EC. Mucormycosis of the sphenoidal sinus in an otherwise healthy patient. Case report and literature review. J Laryngol Otol 1996;110(5):471-473.

4. Jones AC, Bentsen TY, Fredman PD. Mucormycosis of the oral cavity. Oral Surg Oral Med Oral Pathol 1993;75(4):455-460.

5. Kofteridis DP, Karabekios S, Panagiotides JG, Bizakis J, Kyrmizakis D, Saridaki Z, Gikas A. Successful treatment of rhinocerebral mucormycosis with liposomal amphotericin B and surgery in two diabetic patients with renal dysfunction. J Chemother 2003;15(3):282-286.

6. Chalian, VA, Drane JB, Standish SM. The evolution and scope of maxillofacial prosthetics. In: Chalian VA, Drane JB, Standers SM editors. Maxillofacial Prosthetics: Multidisciplinary Practice. Williams and Wilkins Company; Baltimore: USA, 1972.

7. Beumer J, Curtis TA, Marunick MT. Maxillofacial rehabilitation: prosthodontic and surgical considerations. St Louis: Ishiyaku Euro America;1996. p. 225-229.

8. Keyf F. Obturator prosthesis for hemimaxillectomy patients. J Oral Rehab 2001;28(9):821-829.

9. Yoshida H, Furuya Y, Shimodaira K, Kanazawa T, Kataoka R, Takahashi K. Spectral characteristics of hypernasatity in maxillectomy patients. J Oral Rehab 2000;27(8):723-730.

10. Sykes LM, Wolfaardt JF, Sukha A. Prosthodontic rehabilitation of a patient with total avulsion of the maxilla (a clinical report). J Prosthet Dent 2002;88(4):362-366.

11. Desjardins RP. Obturator prosthesis design for acquired maxillary defects. J Prosthet Dent 1978;39(4):424-435.

12. Wang RR. Sectional prosthesis for total maxillectomy patient. A clinical report. J Prosthet Dent 1997;78(3):241-244.

13. Ash MM. Philosophy of occlusion: past and present. Dent Clin North Am 1995;39(2):233-255.

14. Taylor TD, editor. Clinical Maxillofacial Prosthetics. Chicago: Quintessence 2000;103-120.

15. Jacob RF. Clinical Management of the Edentulous Maxillectomy patient. In: Taylor TD editor. Clinical Maxillofacial Prosthetics, Quintessence Publishing Co, Illinois. 2000. p. 85-102.

16. Murray CG. Re-establishing natural tooth position in the edentulous environment. Aust Dent J 1978;23(5):415-421.

17. Pound E. Utilizing speech to simplify a personalized denture service. J Prosthet Dent 1970;24(6):586-600.

18. Pound E. Let /S/ be your guide. J Prosthet Dent 1977;38(5): 482-489.
19. Zlotolow IM. Dental Oncology and Maxillofacial Prosthetics. In: Shah JP, editor. Cancer of the Head and Neck: Atlas of Clinical Oncology. BC Decker Inc: Hamilton, Ontario; 2001;4: p. 376-373.

20. Tanaka H. Speech patterns of edentulous patients and morphology of the palate in relations to phonetics. J Prosthet Dent 1973; 29(1):16-28.

21. Rothman R. Phonetic considerations in denture prostheses. L Prosthet Dent 1961;11(2):214-223.

22. Petrovic A. Speech sound distortions caused by changes in complete denture morphology. J Oral Rehabil 1985;12(1):69-79.

23. McFarland, Baum SR, Chabot C. Speech compensation to structural modification of the oral cavity. J Acoust Soc Am 1996; 100(2 pt 1):1093-1104.

24. Shehata S. Randomized controlled clinical for verifying the effect of obturators fabricated valplast ${ }^{\circledR}$ materials on masticatory function hemimaxillectomy patients. Egypt Den J 2007; 53(3.3):2453.

25. Singh K, Gupt N. Injection molding technique for fabrication of flexible prosthesis from flexible thermoplastic denture base materials. World J Dent 2012;3(4):303-307.

26. Jain N, Naitam D, Wadkar A, Nemane A, Katoch S, Dewangan A. Prosthodontic Rehabilitation of Hereditary Ectodermal Dysplasia in an 11-Year-Old Patient with Flexible Denture: a case report. 2012, Article ID 489769. p.5.

27. Kumar P, Singh V, Kumar A, Singh HP. Flexible dentures: smile for sorrow faces. Eur J Gen Dent 2012;1(1):66.

28. Lowe LG. Flexible denture flanges for patients exhibiting undercuts, tuberosities and reduced width of buccal vestibule: a clinical report: J Prosthet Dent 2004;13(1);17-27.

29. Keenan PL, Radford DR, Clark KF. Dimensional change in complete denture fabricated by injection moulding and microwave processing. J Prosthet Dent 2003;89(1):37-44.

30. Anderson GC, Schulte JK, Arnold TG. Dimensional stability of injection and conventional processing of denture base acrylic resin. J Prosthet Dent 1988;60(3):394-398.

31. Nogueria SS, Ogle RE, Davis EL. Comparision of accuracy between compression and injection moulded complete dentures. J Prosthet Dent 1999;82(3):291-300.

32. Parvizi A, Lindquist T, Schneider R, et al. Comparison of dimensional accuracy of injection moulded denture base material to that of conventional pressure pack acrylic resin. J Prosthodont 2004;13(2):83-89.

33. Salim S, Sadamori S, Hamanda T. The dimentional accuracy of rectangular acrylic resin specimens cured by three denture base processing methods. J Prosthet Dent 1992;67(6):879-881.

34. Wong DM, Cheng LY, Chow TW. Effect of processing method on dimentional accuracy and water sorption of acrylic resin denture. J Prosthet Dent 1999;81(3):300-304.

35. Hahn GW. A comfortable silicone bulb obturator with or without dentures. J Prosthet Dent 1972;28(3):313-317.

36. Minagi S, Nagare I, Sato M, Sato T. Mushroom-shaped resilient retainer for maxillary obturator prostheses. Int J Prosthodont 1991;4(5):473-476.

37. Parel SM, LaFuenfe H. Single visit hollow obturators for edentulous patients. J Prosth Dent 1978;40(4):426-429.

38. Sykes LM, Coogan MM. Yeast counts as a measure of host resistance in dental patients. J Dent Assoc S Afr 1997;52(1):19-23.

39. Khan Z, Farman AG. The prosthodontist role in head and neck cancer and introduction - Oncologic dentistry. J Ind Prosthodont Soc 2006;6(1):4-9. 